\title{
Fatores mediadores no processo de desenvolvimento profissional de docentes do ensino superior
}

\author{
Marta Almeida ${ }^{1}$ \\ ORCID: 0000-0003-3108-4289
}

\section{Resumo}

0 artigo centra-se no estudo dos processos de desenvolvimento profissional de docentes do ensino superior, em particular no que diz respeito à vertente de ensino. Visando a captar diferentes perfis de orientação pedagógica num grupo de docentes de três escolas superiores de educação da zona geográfica de Lisboa e Vale do Tejo em Portugal e, simultaneamente, perceber que fatores (endógenos e exógenos) contribuem para um maior afastamento ou uma maior aproximação a um perfil pedagógico orientado para a aprendizagem, a pesquisa partiu de entrevistas e de revisão bibliográfica para construir um questionário com três escalas, a saber: níveis de implicação e compromisso pessoal com a profissão, preocupações docentes e fatores de mudança. Os resultados revelam a presença de perfıs de orientação pedagógica distintos, sendo que um grupo evidencia um estádio de desenvolvimento profissional mais inicial, com preocupações essencialmente centradas em si e na proficiência científica; outro, com maior grau de desenvolvimento, orientase hegemonicamente para o aluno e para a aprendizagem; e ainda um outro sem foco dominante, aparentemente reunindo docentes dominados pelas exigências da carreira, particularmente com as imposições na vertente de investigação e produção científica.

\section{Palavras-chave}

Desenvolvimento profissional docente - Orientação pedagógica - Ensino superior.

1- Instituto de Educação da Universidade de Lisboa (UIEDF), Lisboa, Portugal. Contato: mialmeida@ie.ulisboa.pt 


\section{Mediating factors in the professional development process of higher education professors}

\section{Abstract}

The article focuses on the professional development processes of higher education professors, looking especially at the teaching dimension. It aims to capture different profiles of pedagogical orientation in a group of teachers from three higher education institutions located in Portugal, in the Lisbon and Tagus Valley area. Also, it seeks to understand which factors (endogenous and exogenous) contribute to a greater distance or a greater proximity to a learning-oriented pedagogical profile. Interviews and bibliographic review have been the starting point to build a questionnaire with three scales, namely, levels of involvement and personal commitment to the profession, teaching concerns, and factors of change. The results reveal the presence of distinct pedagogical orientation profiles, with one group showing a more primary stage of professional development, basically centered on themselves and on their scientific proficiency; the other group, with a higher degree of development, and hegemonically oriented towards students and their learning; and a third group, without a dominant focus, which apparently brings together teachers influenced by their careers requirements, particularly regarding research and scientific production.

\section{Keywords}

Teacher professional development - Pedagogical orientation - Higher education.

\section{Introdução}

A preocupação com a qualidade do ensino-aprendizagem no ensino superior vem ganhando expressão nos últimos anos, fruto, entre outros, de fenômenos como a massificação do ensino e o aumento das taxas de insucesso nesse setor. A par desta inquietação subentende-se a premência de olhar para os modos como os docentes ensinam, o que, consequentemente, resulta em um escrutínio público da atividade docente mais acentuado do que até aqui.

A preocupação com a melhoria da qualidade docente tem vindo a ganhar protagonismo enquanto prioridade estratégica nas instituições de ensino superior (CIDSABUCEDO, PÉREZ-ABELLÁS; ZABALZA, 2009). Com efeito, o relatório do International Consortium for Educational Development (ICED, 2014), a propósito da preparação dos docentes do ensino superior, ilustra claramente a atenção crescente que esta temática tem recebido, assinalando o desenvolvimento de políticas e práticas de incentivo à melhoria da qualidade dos docentes um pouco por todo o mundo. Na Europa, é no Reino Unido que encontramos sistemas de promoção do desenvolvimento profissional docente com maior tradição e de forma mais generalizada (ELTON, 2009; GIBBS, 2004). Fora da Europa 
encontram-se iniciativas mais desenvolvidas em países como a Austrália, Estados Unidos e Canadá (ALMEIDA, 2018).

Instâncias e organismos internacionais também refletem as preocupações enunciadas e instigam as instituições de ensino superior a equacionar a dimensão da docência e a preparação dos professores que aí atuam. Veja-se a título ilustrativo o relatório da OCDE (GUELLEC et al., 2018) no qual recomenda o incentivo à formação pedagógica dos acadêmicos ou o Processo de Bolonha que deu origem à criação do Espaço Europeu de Ensino Superior, que, em vários dos documentos produzidos, sublinha a premência de valorizar a dimensão pedagógica e de colocar "em primeiro plano a dimensão docente no ensino universitário” (GARCIA-LÓPEZ, 2006, p. 547).

As preocupações com a dimensão docente são legitimadas também se atendermos a dois sinais distintivos do exercício profissional no ensino superior. Por um lado, a ausência de valorização de uma formação pedagógica especializada enquanto requisito de acesso ou de progressão e, por outro lado, a perpetuação de uma cultura de isolamento na vertente docente, contrariamente ao que acontece na vertente da investigação.

A ausência de formação habilitante para o exercício docente é visível logo à entrada na profissão, em que imperam os requisitos de ordem científica, nomeadamente os de uma sólida preparação acadêmica no campo disciplinar e os inerentes à produção científica, restringindo-se o indispensável conhecimento pedagógico a um mero somatório de experiência profissional (ALMEIDA, 2018). A opacidade da formação pedagógica mantémse quando se observa o pouco valor que, em geral, tem para efeitos de progressão na carreira traduzindo-se numa tensão institucional, ainda por resolver, entre o docenteinvestigador e o docente-professor (CLEGG, 2008; ZABALZA, 2004).

$\mathrm{Na}$ verdade, convive-se pacificamente com a noção de que sucesso profissional é sinônimo de produtividade científica, avaliada pela quantidade de estudos e artigos publicados (ARCHER, 2008).

Daqui resulta, desde logo, a perdurada naturalização na docência, presumivelmente decorrente de uma convicção enraizada de que basta saber para saber ensinar (paradigma artesanal) dependendo, em larga medida, das capacidades e propensões particulares de cada um. Como refere Cunha (2010, p. 70):

[...] contrariando a lógica de legitimação dos títulos profıssionais, dos quais a universidade é guardiã, são eles 'práticos' portadores de saberes provenientes do senso comum, desprovidos de teoria e reflexão sistemática.

0 segundo sinal característico do exercício docente no ensino superior prende-se com a prevalência de uma cultura profissional em que se entende o espaço da cátedra como um espaço inviolável, fruto, de alguma forma, do (des)entendimento do significado da reclamada autonomia profissional docente, na qual se consagra a liberdade moral e intelectual para investigar e ensinar, amiúde justificando certo ostracismo profissional (ALMEIDA, 2017). 0 ensino torna-se, assim, pouco permeável a dinâmicas de colaboração entre pares, promotoras de aprendizagem e desenvolvimento profissional, contrariamente ao que acontece se atentarmos às práticas de trabalho em equipe na vertente de investigação. 
Com efeito, a colaboração entre pares não parece ser um exercício valorizado nem pelos docentes, nem pelas organizações (CUNHA 2005; ELTON, 2009; ZABALZA, 2004, 2007). As iniciativas registadas, quando existentes, cingem-se à elaboração de programas e harmonização de processos avaliativos, havendo pouca tradição na partilha de tempos e espaços de sala de aula e no investimento em investigação sobre os processos de ensinoaprendizagem (ALMEIDA, 2017).

Acresce a tudo o que foi exposto a urgência de generalizar os postulados do paradigma da aprendizagem, no qual se pugna pelo abandono de práticas de ensino magistral que têm pautado o exercício docente no ensino superior. Com efeito, na literatura, reitera-se o discurso instigando à mudança de paradigma educacional (BOUCHER; DESGAGNÉ, 2001 ; FLORES; DAY; VIANA, 2007; TILLEMA, 2005).

Ora, em virtude dos argumentos que foram sendo apresentados, não será inusitado afirmar-se a urgência em investir em processos que promovam a aprendizagem e o desenvolvimento profissional docente dos que atuam no ensino superior, e que, para que tal aconteça, ser determinante o grau de compreensão alcançado relativamente aos processos de desenvolvimento profissional desses atores, nomeadamente, conhecendo os fatores que podem contribuir para acelerar ou, ao invés, impedir essa evolução.

0 estudo de que se dá conta neste texto procurou, assim, avançar na compreensão do processo de desenvolvimento profissional, particularmente atento ao que acontece na dimensão docente, buscando a desocultação de fatores que medeiam esse processo.

Por limitações de ordem logística e temporal, o estudo circunscreveu-se a uma área específica - a formação inicial de professores do ensino superior politécnico, tendo também delimitado como zona geográfica de recorte a região portuguesa de Lisboa e Vale do Tejo. A opção por esse grupo de docentes em particular não é alheia ao que se considera serem traços inconfundíveis e únicos de um grupo que ensina a ensinar, a que se soma a possibilidade de abranger, simultaneamente, docentes originários de diversas áreas dado o caráter pluridisciplinar dos cursos de formação de professores.

0 estudo foi desenhado procurando a complementaridade entre dados de natureza qualitativa e quantitativa, enquadrando-se assim numa abordagem mista, que se operacionaliza na recolha de informação passivel de possibilitar a identificação de diferentes perfis de orientação pedagógica no grupo de docentes estudado e, concomitante, perceber quais fatores condicionantes do desenvolvimento profissional emergem.

0 texto elucida o quadro teórico-conceitual em que se apoia o estudo, clarificando conceitualmente e enunciando os postulados que se adotam quando se alude ao processo de desenvolvimento profissional. Na sequência, passa-se à explanação de modelos de desenvolvimento profissional especificamente orientados para a compreensão das trajetórias docentes no ensino superior e, por fim, discutem-se potenciais fatores associados ao desenvolvimento profissional docente. Segue-se a seção destinada à metodologia. Logo após apresentam-se os principais resultados, avançando, em simultâneo, com a discussão dos achados da pesquisa. Encerra-se o texto com algumas considerações finais acerca do trabalho desenvolvido. 


\section{Desenvolvimento profissional: um conceito ambíguo}

0 conceito de desenvolvimento profissional é de natureza polissêmica, amiúde confundindo-se com expressões como mudança, aprendizagem, transformação, aperfeiçoamento, entre outras. Na literatura, encontram-se duas grandes linhas. Uma que integra a investigação em torno de modelos explicativos das transformações que se operam nas formas de pensar e de agir dos professores, outra em que desenvolvimento profissional é sinônimo de formação. A distinção entre essas duas correntes é apresentada por Estrela, A; Estrela, M (2006). Para os autores, na primeira, e na qual se situa o presente estudo, enquadra-se o que Cruz Tomé (1999) designa de tese da inclusão, em que se considera o desenvolvimento do indivíduo como um processo complexo e multidimensional, abarcando os mecanismos de promoção desse desenvolvimento, entre os quais a formação. Nesse sentido, segundo Estrela, A; Estrela, M (2006, p. 75), o desenvolvimento profissional decorre:

[...] de uma pluralidade de factores, entre os quais se contam os que se referem ao desenvolvimento da pessoa do professor, numa perspectiva de life span, às actividades organizadas de formação contínua e às actividades individuais de auto-promoção.

Na segunda linha, denominada tese da equivalência (CRUZ TOMÉ, 1999), desenvolvimento profissional confunde-se e esgota-se no conceito de formação contínua sendo, por conseguinte, uma linha mais limitada. 0 conceito de desenvolvimento profissional que aqui se assume permite ir além da ideia de formação permanente, formação contínua, formação em serviço, desenvolvimento ao longo da vida, cursos de reciclagem ou capacitação (DAY, 2001; ESTRELA, A; ESTRELA, M, 2006; MARCELO, 2009; MORAIS; MEDEIROS, 2007), implicando a aprendizagem permanente.

0 conceito de desenvolvimento profissional é também frequentemente associado à noção de carreira. No entanto, apesar de ser possível perspectivar influências entre os dois processos, esses distinguem-se. Para Kats e Coleman (2002), o estádio de carreira consiste em um período caraterizado por um conjunto de atividades e tarefas distintivas de estádios anteriores. Embora sendo expectável que a carreira (e os seus desafios) seja um dos fatores que influem no processo de crescimento pessoal e profissional, não é linear que os diversos patamares da carreira conduzam a desenvolvimento profissional.

Em torno do conceito de desenvolvimento profissional, surge também o equívoco de considerá-lo como equivalente ao conceito de mudança. Se é certo que o processo de que se fala obriga a transformações ao longo do tempo, implicando mudanças de formas simples para formas mais complexas (BURDEN, 1990), uma mudança pode não significar evolução mas tão somente decorrer de uma necessidade de sobrevivência (de indivíduos ou instituições), sendo, por isso, uma mudança fortuita de natureza adaptativa a circunstâncias, podendo até implicar retrocessos ou o abandono da trajetória de desenvolvimento desejada (ZABALZA, 2004).

Para que se observe desenvolvimento profissional, terá que haver, é certo, aprendizagem e, nesse sentido, terão que se operar mudanças nas concepções e nas 
práticas, sendo para isso fundamental uma implicação ativa do sujeito num processo de "crescimento compreensivo do professor" (G00DWIN, 2005, p. 232).

Por fim, é fundamental reconhecer a complementaridade entre a dimensão individual e a dimensão organizacional na abordagem ao conceito de desenvolvimento profissional. Com efeito, a direção que o desenvolvimento profissional de cada indivíduo assume é sempre resultado, por um lado, das suas biografias pessoais e, por outro, de influências (diretas e indiretas) que os contextos exercem sobre ele (DAY, 2001; DESIMONE, 2009; FEIXAS, 2002; KNIGHT; TAIT; YORKE, 2006). Dessa forma, entende-se que:

[...] o sentido do desenvolvimento profissional dos professores depende das suas vidas pessoais e profissionais e das políticas e contextos escolares nos quais realizam a sua atividade docente. (DAY, 2001, p. 15).

$\mathrm{Na}$ literatura assinala-se ainda o efeito recíproco do desenvolvimento profissional no desenvolvimento das organizações, devendo o primeiro ser assumido como uma forma de desenvolvimento do segundo (CLEGG, 2008; FERNÁNDEZ CRUZ, 2006; DAY, 2001; FEIXAS, 2002; MARCELO, 2009; MORAIS; MEDEIROS, 2007; ZABALZA, 2004).

\section{Modelos de desenvolvimento profissional docente}

A oferta de modelos explicativos do processo de desenvolvimento profissional docente no ensino superior, apesar de não ser abundante, integra alguns contributos que permitem avançar na compreensão desse fenômeno.

Encontram-se propostas que, pelo fato de incidirem numa única dimensão ou período específico, não permitem uma compreensão holística do fenômeno. Por exemplo, o modelo de Nyquist; Sprague (1998) abrange apenas as características cognitivas e emocionais dos docentes na fase inicial da carreira e a proposta de Kalivoda et al. (1994) foca-se no stress e frustração, evidenciando diferentes níveis de vitalidade ao longo do percurso profissional.

Já especificamente sobre o desenvolvimento profissional na vertente docente, encontramos três propostas. As duas primeiras são de Kugel (1993) e Robertson (1999) que serviram de inspiração à proposta mais recente apresentada por Feixas (2002). Observe-se em detalhe cada uma dessas propostas.

0 modelo de Kugel (1993) contempla duas grandes fases. Na primeira, o docente tem como foco o ensino, na segunda, a aprendizagem. Enquanto focado no ensino, o docente poderá passar por três estágios, começando por demonstrar uma preocupação consigo e com a imagem que os outros têm de si, seguindo-se a preocupação com a proficiência ao nível dos conteúdos e, por fim, dá-se um acentuar da preocupação com o estudante, embora ainda percebido como ator passivo. A segunda fase tem início quando o docente passa a aceitar o aluno como agente ativo, sendo a última barreira ultrapassada quando o estudante é percebido como aprendente autónomo, capaz de traçar o seu próprio percurso de aprendizagem.

0 autor supracitado argumenta que a passagem de um estádio para outro acarreta uma mudança no foco das preocupações, considerando que essas modificações ocorrem 
devido à resolução de preocupações que vão, assim, requerendo menos esforço e investimento, permitindo, então, que novas preocupações despontem.

Na mesma linha do autor anterior, Robertson (1999) defende que o desenvolvimento profissional não é mais do que um processo de ampliação das dimensões pré-existentes ou de extensão do sistema, pela integração de uma nova dimensão que passa a ser dominante face às pré-existentes. 0 autor alega que, numa primeira fase, o docente está centrado no ensino (fase egocentrismo), passando ulteriormente a estar mais focado na aprendizagem (fase aliocentrista). A grande novidade da proposta de Robertson face à de Kugel (1993) é a inserção de uma terceira fase contemplando as duas fases anteriores de forma integrada. Nessa derradeira fase, ensino e aprendizagem são percebidos como um sistema dinâmico e complexo (fase sistemocentrista). A transição entre etapas decorre, para o autor, de processos de aprendizagens transformativas que acontecem quando o sujeito verifica que algo que constituía uma certeza na sua forma de pensar e agir não resulta, pelo que põe em causa o seu quadro de referências. Segue-se, então, um período de incertezas, desorientação e experimentação até as novas perspectivas serem integradas no sistema de referências.

Mais recentemente, Feixas (2002), baseando-se nos trabalhos anteriores, apresenta um modelo de três estádios: centrado em si mesmo, centrado em si e no ensino, centrado no estudante e na sua aprendizagem. Trata-se de um trabalho em que procura uma abordagem mais holística, analisando em cada etapa três dimensões: a dimensão pessoal (traços de personalidade, preocupações, capacidade de empatia), a docente (conteúdos, dinâmicas, concepções) e a relacional (alunos, colegas, instituição).

Nas propostas discutidas fica evidente o entendimento generalizado de que a orientação para o aluno e para a aprendizagem corresponde ao expoente máximo em termos de desenvolvimento profissional. Estudos como o de Trigwell; Prosser; Waterhouse (1999), em que se comprova a existência de uma relação direta entre a orientação de ensino e a qualidade das aprendizagens dos alunos, revelam que a orientação mais favorável será a que se foca no aluno e na aprendizagem. Prosser et al. (2003), por seu turno, demonstram que professores centrados nos conteúdos são associados pelos alunos a fracas oportunidades de aprendizagem e a um menor nível de qualidade.

Um segundo aspecto transversal nos estudos discutidos prende-se com o recurso à perscrutação das preocupações como forma de determinar a orientação pedagógica dos docentes, alicerçando-se nos trabalhos precursores de Fuller (1969). Parte-se, assim, do pressuposto de que as transformações resultantes dos processos de desenvolvimento profissional afetam as preocupações declaradas pelos sujeitos, que serão de diferentes ordens consoante a orientação pedagógica dominante (TRIGWELL; RAMSDEN; MIDDLETON, 2006; TRIGWELL et al., 2008).

\section{Fatores interferentes no desenvolvimento profissional}

Procurar-se-á agora dar prosseguimento à reflexão iniciada, examinando o que pode justificar o fato de uns docentes atingirem a condição de peritos e outros não. Se atendermos à consideração inicial em que se avançou com o postulado de que o processo de desenvolvimento profissional implica mudança e aprendizagem ao longo da vida, será 
inevitável aceitar a interferência de fatores endógenos e exógenos, sendo que uns poderão facilitar esse processo e outros, ao invés, serão prejudiciais (DAY, 2001; ZABALZA, 2004). Para Marcelo (2009) conhecer e compreender esses fatores é fundamental, pois como refere:

[...] se se quer facilitar o desenvolvimento profissional temos que perceber o processo mediante $o$ qual os professores crescem profissionalmente, bem como as condições que ajudam e promovem esse crescimento. (MARCELO, 2009, p. 16).

$\mathrm{Na}$ acepção de desenvolvimento profissional que se adota, importa reconhecer a importância dos fatores de índole pessoal e contextual, a partir da entrada na profissão nos processos de socialização profissional (COHEN-SCALI, 2003; FLORES, 2004; HARLAND; STANIFORTH, 2006).

No cenário traçado, entende-se que o desenvolvimento profissional será resultado de uma combinatória das biografias pessoais e das influências, diretas e indiretas, que os contextos exercem sobre ele. De forma recíproca, reconhece-se que o desenvolvimento organizacional dependerá, em larga medida, dos níveis de maturação profissional dos seus atores (CLEGG, 2008; FERNÁNDEZ CRUZ, 2006; DAY, 2001; DESIMONE, 2009; KNIGHT; TAIT; YORKE, 2006; MARCELO, 2009; ZABALZA, 2004).

Os fatores de natureza pessoal, sejam eles cognitivos, psicológicos, biológicos, ou outros, abrangem também mecanismos individuais de atribuição de sentido e de ação em contexto, a que se soma o esquema de equilíbrio entre a esfera privada e a esfera profissional traçado por cada um (ALMEIDA, 2014). Nos fatores endógenos podem influir elementos como o grau de consciencialização de si enquanto docente, o grau de compromisso e motivação, a par de outras competências emocionais e sociais (MORA; GOMES, 2007).

Os fatores externos são inerentes às características e dinâmicas dos contextos socioprofissionais com que os docentes interatuam (exemplo, as condições de trabalho, a cultura institucional), não sendo por isso de estranhar que se considere que o investimento em processos que potenciem a melhoria da qualidade docente têm que ser uma preocupação das instituições de ensino superior (CID-SABUCEDO, PÉREZ-ABELLÁS; ZABALZA, 2009; GARCIA-LÓPEZ, 2006).

\section{Orientações metodológicas e processuais}

Tendo como propósito contribuir para o entendimento sobre o modo como se processa o desenvolvimento profissional dos docentes do ensino superior, procurou-se, em simultâneo, detectar fatores que poderão afetar esse processo, seja estimulando-o ou impedindo-o.

Não podendo abarcar toda a diversidade de contextos de atuação docente, optou-se por limitar os participantes do estudo àqueles que atuam na formação inicial de professores, área de formação que garantiria, entre outros aspectos, a presença de um corpo docente de natureza multidisciplinar.

Integrando-se numa abordagem mista, com recurso a técnicas qualitativas e quantitativas, o estudo contemplou a realização de entrevistas semidiretas em profundidade 
que, conjuntamente com a revisão da literatura e análise documental, permitiram a construção, validação e a aplicação de um questionário a docentes envolvidos na formação de professores no subsistema de ensino superior politécnico público da região portuguesa de Lisboa e vale do Tejo.

\section{O instrumento}

0 questionário integra três escalas. A primeira destina-se a averiguar que aspectos da profissão motivam ou atraem os docentes. A segunda está especialmente vocacionada para identificar perfis de orientação pedagógica através das preocupações dos docentes, estruturando-se em três subdimensões conceituais. As subdimensões representam um perfil focado em si e no domínio dos conteúdos, um outro focado nos processos de ensino e um terceiro focado no aluno e na aprendizagem. A terceira escala prende-se com a identificação de fatores que poderão operar mudanças nos professores, incluindo fatores internos e externos ao sujeito. Foi também selecionado um conjunto de variáveis sociodemográficas (gênero, idade, experiência profissional no ensino superior, experiência de ensino em outros níveis de escolaridade, área científica de formação, categoria profissional, instituição de pertença e formação pedagógica) para aferir a sua interferência no posicionamento dos docentes.

Trata-se de um questionário de opinião multidimensional estruturado a priori, que pretende, através de cada escala construída, medir uma variável ou dimensão considerada relevante para os propósitos do estudo. 0 instrumento construído enquadrase maioritariamente no modelo aditivo ou escala de Likert (MOREIRA, 2004). A escala de resposta adotada compreende cinco pontos, permitindo ao inquirido posicionar-se entre a total discordância (1) até a total concordância (5).

0 processo de validação do instrumento visou a assegurar a validade do conteúdo (MOREIRA, 2004), isto é, o grau em que os conteúdos incorporados em cada escala se referem de modo apropriado ao que se pretende medir, tendo sido aplicado a um grupo de sujeitos com caraterísticas semelhantes à população a abranger. Posteriormente, a aplicação do índice de precisão de Cronbach, conhecido como coeficiente alfa, permitiu aferir a consistência interna de cada escala ou das suas subdimensões, no caso da escala referente aos perfis de orientação pedagógica. Os resultados apurados são bastante satisfatórios ${ }^{2}$, revelando um elevado nível de consistência interna em todas as escalas e subescalas.

\section{Apresentação e discussão dos resultados}

\section{Caraterização dos inquiridos}

Foram distribuídos 152 questionários obtendo-se uma taxa de resposta de 55\%. No grupo de respondentes verificou-se o predomínio do gênero feminino e das faixas etárias

2- 0,845 (eixo implicação e compromisso pessoal); 0,912 (eixo perfis); 0,871 (eixo fatores); 0,812 (eixo fatores/formação) e, no caso das subescalas construídas em função dos três perfis de orientação, regista-se os valores de 0,823 (perfil A); 0,814 (perfil B) e 0,829 (perfil C). 
dos 50-59 anos e dos 30-39 anos, sendo maioritariamente oriundos de áreas das Ciências Humanas e com o grau de mestre.

Os docentes tinham experiência de ensino no ensino superior variável, com maior prevalência de grupos de docentes com pouca experiência (até cinco anos) e mais experientes (mais de 20 anos). Maioritariamente fizeram a sua formação inicial em cursos vocacionados para o ensino e tinham experiência de ensino anterior à entrada no ensino superior.

\section{Identificação de grupos em função dos perfis de orientação pedagógica}

$\mathrm{Na}$ impossibilidade de proceder à análise fatorial quer pela dimensão da amostra ( $\mathrm{N}$ inferior a 100), quer seguindo a regra do rácio entre o número de casos e o número de variáveis ser, no mínimo, de 5/1 (HILL, M; HILL, A, 2005), optou-se pela extração de clusters através do procedimento não hierárquico K-Means. Esse método calcula os centroides (média de todos os sujeitos em cada uma das variáveis de medida) sendo que os sujeitos são agrupados nos clusters de cujos centroides se encontram mais próximos. Este procedimento permitiu agrupar num primeiro grupo 19 professores (cluster 1), 29 professores num segundo (cluster 2) e 24 professores no terceiro (cluster 3).

Posteriormente à extração dos grupos, procedeu-se à análise da estatística $\mathrm{F}$ da Anova, que indicou que os clusters seriam significativamente diferentes nos três perfis ${ }^{3}$.

A análise do teste de comparação múltipla a posteriori revelou que os clusters apresentam diferenças significativas no agrupamento de itens do Perfil A (orientado para si), sendo que o cluster 2 apresenta a média mais elevada $(4,24)$ enquanto o cluster 3 apresenta a média mais baixa $(3,33)$ (tabela 1$)$.

Tabela 1 - Teste de Tukey: Perfil A

\begin{tabular}{ccccc:c}
\hline \multirow{2}{*}{ Cluster } & & \multicolumn{4}{c}{ Subset for alpha $=0.05$} \\
\cline { 3 - 6 } & & $\mathrm{N}$ & 1 & 2 & 3 \\
\hline Cluster 3 & 24 & 3,3307 & & \\
\hline Cluster 1 & 19 & & 3,6908 & \\
\hline Cluster 2 & 29 & & & 4,2414 \\
\hline Sig. & & 1,000 & 1,000 & 1,000 \\
\hline
\end{tabular}

Fonte: elaboração a partir dos dados da pesquisa.

Os clusters apresentam diferenças significativas também no agrupamento de itens do Perfil B (orientado para o ensino), sendo que o cluster 2 apresenta a média mais elevada $(4,38)$ enquanto o cluster 3 apresenta a média mais baixa $(3,54)$ (tabela 2$)$.

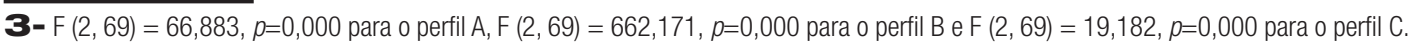


Tabela 2 - Teste de Tukey. Perfil B

\begin{tabular}{|c|c|c|c|c|}
\hline \multirow{2}{*}{ Cluster } & \multirow[b]{2}{*}{$\mathrm{N}$} & \multicolumn{3}{|c|}{ Subset for alpha $=0.05$} \\
\hline & & 1 & 2 & 3 \\
\hline Cluster 3 & 24 & 3,5417 & & \\
\hline Cluster 1 & 19 & & 3,8388 & \\
\hline Cluster 2 & 29 & & & 4,3879 \\
\hline Sig. & & 1,000 & 1,000 & 1,000 \\
\hline
\end{tabular}

Fonte: elaboração dos autores a partir dos dados da pesquisa.

Relativamente ao Perfil C (orientado para a aprendizagem), o cluster 3 apresenta a média mais elevada $(4,33)$, enquanto o cluster 1 apresenta a média mais baixa $(3,73)$. As diferenças entre o cluster 3 e 2 não são estatisticamente significativas (tabela 3).

Tabela 3 - Teste de Tukey: Perfil C

\begin{tabular}{|c|c|c|c|c|}
\hline \multirow{2}{*}{ Cluster } & \multirow[b]{2}{*}{$\mathrm{N}$} & \multicolumn{3}{|c|}{ Subset for alpha $=0.05$} \\
\hline & & 1 & 2 & 3 \\
\hline Cluster 1 & 19 & 3,7336 & & \\
\hline Cluster 2 & 29 & & & 4,2198 \\
\hline Cluster 3 & 24 & & & 4,3307 \\
\hline Sig. & & 1,000 & 1,000 & ,490 \\
\hline
\end{tabular}

Fonte: elaboração a partir dos dados da pesquisa.

Os professores do cluster 1 são os que mais se afastam das preocupações relacionadas com o aluno e a aprendizagem, estando mais focados em si e no processo de ensino. 0 cluster 2 parece agrupar docentes em que não se denota um perfil de orientação predominante, sinal de que nem todos os docentes relativizam umas preocupações quando assumem outras. No cluster 3 evidencia-se uma diminuição das preocupações das etapas anteriores para valorizar essencialmente os processos de aprendizagem e o aluno.

\section{Influência de variáveis sociodemográficas}

0 teste Qui-quadrado de independência apenas revela diferenças decorrentes do gênero verificando-se uma maior proporção de professoras no cluster 3, para as quais não se tem explicação. Não foram encontradas outras diferenças significativas relativamente às variáveis sociodemográficas anteriormente referidas. Esses resultados corroboram as conclusões do estudo de Trigwell; Prosser; Taylor (1994), no qual se detectaram níveis de desenvolvimento profissional avançados logo no início da carreira, sinal de que nem a idade, nem a experiência são por si só fatores determinantes. Mais ainda, estes resultados apontam fortemente para a insuficiência de se proceder a uma análise de isolada de fatores interferentes nos processos de desenvolvimento profissional, sugerindo processos mais complexos de interdependência entre estes. 


\section{Níveis de compromisso e implicação pessoal}

Avançando na análise, procurou-se perceber se existiriam variações relativamente aos fatores de atração da profissão entre clusters (tabela 4). Para o efeito recorreram-se aos testes de Kruskal-Wallis (para verificação da existência de diferenças estatisticamente significativas) e de Tukey (comparação múltipla a posteriori) (tabela 5).

Tabela 4 - Clusters versus Fatores de atração (Kruskal-Wallis)

\begin{tabular}{c|c:c:c}
\hline Item & Chi-Square $\left(\chi^{2}\right)$ & Gl (KW) & ${\text { Sig. }{ }^{*}(\mathrm{p})}$ \\
\hline 11.6 & 9,247 & 2 &, 010 \\
\hline 11.9 & 5,995 & 2 &, 050 \\
\hline 11.17 & 6,939 & 2 &, 031 \\
\hline 11.18 & 16,414 & 2 &, 000 \\
\hline 11.19 & 6,176 & 2 &, 046 \\
\hline 11.20 & 6,485 & 2 &, 039 \\
\hline
\end{tabular}

${ }^{*} p \leq 0,05$

Fonte: elaboração a partir dos dados da pesquisa.

Como se observa, o cluster 2 concorda especialmente com a importância de "ser reconhecido pelos meus pares pela minha competência pedagógica” (item 11.6). 0 mesmo teste revela os docentes deste cluster também tendem manifestar um maior grau de identificação com as ideias "ser reconhecido no mundo académico pela minha competência científica" (11.9), "ter oportunidade de estabelecer relações com pessoas de reconhecido mérito académico e científico" (11.17), "poder apresentar resultados da minha investigação (publicações, comunicações etc.)” (11.20) do que no cluster 3.

Parece, pois, que o reconhecimento pelos outros é especialmente importante para os docentes do cluster 2. Poder-se-á pressupor que o fato de simultaneamente evidenciarem preocupações de todos os tipos sem foco claro, estará associado a uma necessidade ou dependência do reconhecimento pelos outros (BIGGS, 2006).

0 cluster 1 é o que menos interesse manifesta na "possibilidade de trabalhar em colaboração com colegas de diferentes áreas numa perspectiva interdisciplinar" (11.18), o que se poderá dever ao fato de os docentes estarem mais focados nos conteúdos disciplinares, possivelmente ainda com pouco espaço para ajustar e integrar uma perspectiva interdisciplinar. Também é neste grupo que "a possibilidade de estar em permanente atualização na área das novas tecnologias” (11.19) parece menos atraente.

\section{Diferenças nos fatores reconhecidos como condicionantes}

Quanto à verificação de distinções entre os grupos na sinalização de fatores que concorreram para a mudança, recorreu-se ao teste de Kruskal-Wallis (tabela 5): 
Tabela 5 - Clusters versus Fatores de Mudança (Kruskal-Wallis)

\begin{tabular}{|c|c|c|c|}
\hline Item & Chi-square $\left(\chi^{2}\right)$ & $\mathrm{Gl}(\mathrm{KW})$ & $\operatorname{Sig}^{*}(p)$ \\
\hline 15.1 & 12,185 & 2 & ,002 \\
\hline 15.18 & 6,038 & 2 & ,049 \\
\hline 15.22 & 11,967 & 2 & ,003 \\
\hline 15.24 & 6,645 & 2 & , 036 \\
\hline 15.26 & 8,059 & 2 & ,018 \\
\hline
\end{tabular}

${ }^{*} p \leq 0,05$

Fonte: elaboração a partir dos dados da pesquisa.

Face à existência de diferenças (tabela 5) avançou-se com o teste de Tukey para explorar os resultados. Constata-se que os docentes dos clusters 2 atribuem maior relevância "à necessidade de cumprir requisitos para progressão na carreira" (15.1), sendo prioritária comparativamente ao cluster 3. Associando esses dados a uma maior necessidade de reconhecimento e a uma maior motivação para apresentar resultados da investigação, como se viu no ponto anterior, será esse um grupo particularmente focado na carreira e na investigação.

Ainda no cluster 2 atribuem particular influência "à gestão do tempo em função de outras atividades inerentes ao exercício profissional (ex.: docência/investigação/ gestão)" (15.22), comparativamente aos restantes clusters, valorizando mais que o cluster 1 "experiência enquanto aluno (a)/formando (a) que me possibilitou a observação de outros professores" (15.18), "o desempenho de outros cargos/funções na instituição (ex. coordenação, direção etc.) (15.24) e "as exigências e responsabilidades da minha vida pessoal e familiar (com filhos, familiares idosos etc.) (15.26).

\section{Postura face à formação contínua}

Examinou-se ainda de que forma os clusters diferem entre si relativamente à postura face à necessidade de formação contínua (tabela 6).

Tabela 6 - Clusters versus Formação contínua (Kruskal-Wallis)

\begin{tabular}{ccccccc}
\hline Item & $\vdots$ & Chi-square $\left(\chi^{2}\right)$ & $\vdots$ & Gl (KW) & \multicolumn{2}{c}{ Sig. ${ }^{*}(\mathrm{p})$} \\
\hline 17.1 & $\vdots$ & 11,224 & $\vdots$ & 2 & $\vdots$ &, 004 \\
\hline 17.6 & $\vdots$ & 13,311 & $\vdots$ & 2 & $\vdots$ &, 001 \\
\hline 17.7 & $\vdots$ & 6,708 & $\vdots$ & 2 & $\vdots$ &, 035 \\
\hline 17.8 & $\vdots$ & 13,269 & $\vdots$ & 2 & $\vdots$ &, 001 \\
\hline 17.9 & $\vdots$ & 6,698 & $\vdots$ & 2 & $\vdots$ &, 035 \\
\hline 17.10 & $\vdots$ & 11,341 & $\vdots$ & 2 & $\vdots$ &, 003 \\
\hline
\end{tabular}

${ }^{*} p \leq 0,05$

Fonte: elaboração a partir dos dados da pesquisa. 
Os docentes do cluster 3 consideram que "a formação poderá contribuir para melhorar o meu desempenho como docente se for desenvolvida no seio da instituição onde ensino, com a criação de grupos de trabalho interdisciplinares" (17.1), distinguindo-se do cluster 1. Também reconhecem que "a formação poderá contribuir para melhorar o meu desempenho como docente se for proporcionada em cursos estruturados e organizados por instituições especializadas na área em que me interessa obter formação" (17.7), comparativamente ao cluster 2. Por seu turno, esses últimos concordam que "a formação poderá contribuir para melhorar o meu desempenho como docente se incidir sobre a área científica das disciplinas que leciono" (17.6), afastando-se da posição dos docentes do cluster 3.

Os resultados apontados sugerem que o cluster 3 está particularmente predisposto para uma formação de característica interdisciplinar, sugerindo uma maior descentralização do seu território do que os restantes grupos.

0 cluster 2 distingue-se do 3 e revelam ao manifestar maior interesse numa formação a "incidir sobre modelos de formação de professores" (17.9) e "se for orientada por colegas mais experientes (sistema tutorial)" (17.10), mostrando também uma maior preferência para formação a "incidir na investigação e reflexão sobre as práticas" (17.8) que o cluster 1 , expectável quando os docentes desse último grupo estão centrados em si e nos conteúdos.

\section{Considerações finais}

Os resultados obtidos permitem destacar alguns aspectos, uns referentes às características do grupo estudado e que podem só verificar-se no contexto das escolas superiores de educação portuguesas. Referem-se os dados que revelam uma forte presença de professores com formação e experiência profissional em outros níveis de ensino, levando a inferir que a formação obtida para a qualificação para o ensino e/ou a experiência profissional anterior são apreciadas e valorizadas neste contexto. Com efeito, parece haver um reconhecimento tácito dos saberes pedagógicos para o exercício profissional, embora não sejam requisitos formais de acesso à profissão.

Apesar do aparente reconhecimento tácito do valor da experiência e formação anterior, a análise não revelou diferenças nas preocupações dos docentes com e sem formação/experiência em outros níveis de escolaridade. Presumivelmente, esses dados decorrerão de uma sobrevalorização da prática como fonte de aprendizagem como salientam Zabalza (2007) e Cunha (2010). Na verdade, a experiência per se pode ser limitadora, confinando a atuação do professor à repetição dos modelos observados e a uma prática rotineira (KORTHAGEN, 2009; SHÖN, 1992; ZABALZA, 2007; ZEICHNER, 1993; entre outros).

Denota-se também uma crença com alguma expressão na cultura acadêmica da transferibilidade dos saberes adquiridos para o exercício profissional em outros contextos de ensino para a docência no ensino superior, que, coexistindo com a tradição da "naturalização" no ensino superior (CUNHA, 2010; PILL, 2005; RAMSDEN, 2003; ZABALZA, 2007), contribuem, assim, para um desapreço relativamente à pedagogia do ensino superior (DE KETELE, 2003; ESTRELA, 2010; LEITE; RAMOS, 2010; ZABALZA, 2004). 
Para além das características evidenciadas pelo grupo, foi possível agrupar os docentes em três subgrupos distintos. Um primeiro grupo, cluster 1, que junta menos professores, e que são mais centrados em si e no ensino. São os que menos revelam preocupações com o aluno e com a aprendizagem. É de assinalar que esse grupo não se distingue dos outros em relação à idade ou experiência, o que sustenta a importância de investir em sistemas de apoio ao desenvolvimento profissional independentemente da idade e experiência acumulada.

0 cluster 2 é o mais sui generis pelo fato de não revelar um foco central nas suas preocupações. Esse grupo, que agrega o maior número de docentes, acabou por ser o mais surpreendente, uma vez que não se tem notícia de um grupo semelhante na literatura. Contrariamente ao sugerido nos modelos estudados, parece que nem todos os docentes relativizam umas preocupações quando assumem outras. Poder-se-ia supor que estariam numa fase de integração mais próxima do estádio sistemocentrista proposto por Robertson (1999). No entanto, esta conjectura fica abalada quando se analisa o seu posicionamento face aos fatores de atração ou aos fatores condicionantes, parecendo que a dispersão na docência se deve ao fato de estar mais dependente de motivações e reconhecimento externo e de ser dada maior atenção à carreira, focando-se prioritariamente na vertente da investigação. Será, então, que em vez de um grupo de profissionais autônomos, reflexivos e com uma visão integrada se tratará de um grupo de professores angustiado e confuso, assolado por múltiplas preocupações, vivendo contradições internas entre o que realmente o preocupa e os jargões e discursos partilhados pela comunidade profissional em que se insere?

Por fim, o terceiro grupo de docentes (cluster 3), o segundo maior grupo extraído, aproxima-se da adoção do paradigma da aprendizagem, ao manifestar prioritariamente preocupações com o aluno e a aprendizagem. Com efeito, os resultados bastante animadores parecem evidenciar, como refere Fernández Cruz (2006, p. 10):

o compromisso educativo que se concretiza na preocupação com o aluno. 0 compromisso supera os objectivos da aprendizagem da própria matéria e situa-se na órbita do sentido que a experiência escolar tem para o desenvolvimento do aluno, para o seu futuro, para a vida mais além da escola.

Como se viu, as variáveis independentes selecionadas não explicam a constituição dos grupos. Parece, pois, não ser possivel explicar as diferenças encontradas através da análise de fatores isolados, sugerindo que se está em presença da interferência de múltiplos fatores (endógenos e exógenos) em configurações complexas e dinâmicas, variando de individuo para indivíduo. Essa ideia é reforçada, quando, por exemplo, se verifica que os docentes do cluster 2 revelam alguma ambivalência por ter que responder a exigências das distintas vertentes profissionais, não estando ainda resolvida a tensão entre ensino e investigação. Os trabalhos de Prosser et al. (2008) sublinham a importância dessa articulação, sustentando que uma abordagem mais complexa e holística dos conteúdos está associada a uma orientação para a aprendizagem, potenciada pela integração da atividade de investigação na sua atividade docente, designada por Trigwel e Shale (2004) como ressonância pedagógica. 
Os resultados apurados no que diz respeito ao contributo da formação enquanto prática indutora de desenvolvimento profissional revelam que, não sendo esta variável determinante na constituição dos clusters, contribui para algumas diferenças. Por exemplo, a manifestação de interesse por formação mais transversal e de cariz interdisciplinar é particularmente visível no grupo com perfil de orientação para a aprendizagem. Esses resultados parecem sustentar a ideia segundo a qual o foco das preocupações poderá gerar um tipo de necessidades de formação que não é sentida em fases anteriores, levando o docente a investir na procura de soluções/respostas para os fenômenos que agora o inquietam.

Apesar das limitações decorrentes da reduzida dimensão do grupo estudado, parece sair reforçada a necessidade de investir mais no estudo dos processos de desenvolvimento profissional docente, não só porque se trata de um processo altamente complexo, mergulhado numa intrincada teia em que fatores sociais e pessoais se cruzam, criando contradições e tensões (coexistência de múltiplas lógicas), como pela necessidade de criar sistemas que possam favorecer e acelerar esse desenvolvimento.

Será importante alargar o estudo a grupos de outras áreas de formação ou abrangendo contextos acadêmicos diversos em que a pressão em torno da produção científica se amplifique como é o caso do sistema universitário em Portugal.

Os resultados permitem sustentar a importância de se gerarem políticas e dinâmicas de apoio à aprendizagem e ao desenvolvimento profissional, adequadas aos diferentes contextos e que, concomitantemente, permitam a recondução da dimensão docente a um lugar paritário com as demais vertentes que caracterizam a atuação docente no ensino superior.

Com efeito, é paradoxal que, atribuindo-se à academia a responsabilidade pela construção de conhecimento sustentador do ato de ensinar, em que este saber é ele próprio objeto de ensino, não se valorize e não se promova o acesso a esse saber no seu próprio seio (CUNHA, 2010; ELTON, 2009; TARDIF, 2000). Já é tempo, como afirmam Corrêa e Ribeiro (2013, p. 332), de:

[...] ser construída, coletivamente, uma cultura (um discurso) de valorização da docência na universidade, de modo que o ensino não seja visto como um fardo, mas, ao contrário, como um dos pilares da universidade, uma de suas razões de ser.

\section{Referências}

ALMEIDA, Marta. "De par em par": suas potencialidades e desafios enquanto prática indutora de desenvolvimento profissional docente. In: MOURAZ, Ana; PÊGO, João Pedro (org.). De par em par na Universidade do Porto. Porto: Universidade do Porto, 2017. p. 149-157.

ALMEIDA, Marta. Desenvolvimento profissional e perfis de orientação pedagógica na docência no ensino superior. Sisyphus Journal of Education, Lisboa, v. 6, n. 3, p. 53-75, 2018.

ALMEIDA, Marta. Trajetórias no desenvolvimento profissional docente no ensino superior: fatores condicionantes. Revista Portuguesa de Pedagogia, Coimbra, v. 48, n. 2, p. 61-85, 2014.

ARCHER, Louise. 'Younger academics' constructions of 'authenticity', 'success' and professional identity. Studies in Higher Education, London, v. 33, n. 4, p. 385-403, 2008. 
BIGGS, John. Calidad del aprendizagem universitario. Madrid: Narcea, 2006.

BURDEN, Paul. Teacher development. In: HOUSTON, W. Robert; HABERMAN, Martin; SIKULA, John (org.). Handbook of research on teacher education. New York: MacMillan, 1990. p. 311-328.

BOUCHER, Louis-Philipe; DESGAGNÉ, Yves. Une expérience de transformation des pratiques pédagogiques au primaire: un processus de changement véritable. In: RAYMOND, Danielle (ed.). Nouveaux espaces de développement professionnel et organisationnel. Shrebrooke: CRP, 2001. p. 55-70.

CID-SABUCEDO, Alfonso; PÉREZ-ABELLÁS, Adolfo; ZABALZA, Miguel. Las prácticas de enseñanza declaradas de los "mejores profesores" de la Universidad de Vigo. Relieve, Valência, v. 15, n. 2, p. 1-29, 2009.

CLEGG, Sue. Forms of knowing and academic development practice. Studies in Higher Education, London, v. 34, n. 4, p. 403-416, 2008.

COHEN-SCALI, Valérie. The influence of family, social, and work socialization on the construction of the professional identity of young adults. Journal of Career Development, Missouri, n. 29, p. 237, 2003.

CORREA, Guilherme; RIBEIR0, Victoria. A formação pedagógica no ensino superior e o papel da pósgraduação stricto sensu. Educação e Pesquisa, São Paulo, v. 39, n. 2, p. 319-334, 2013.

CRUZ TOMÉ, Maria África. Proyecto docente: desarrollo profesional del docente. Granada: Universidade de Granada, 1999.

CUNHA, Maria Isabel. Impasses contemporâneos para a pedagogia universitária no Brasil. In: LEITE, Carlinda (ed.). Sentidos da pedagogia no ensino superior. Porto: CIIE, 2010. p. 63-74.

CUNHA, Maria Isabel. 0 professor universitário na transição de paradigmas. São Paulo: Junqueira e Marin, 2005.

DAY, Christopher. Desenvolvimento profissional de professores: os desafios da aprendizagem permanente. Porto: Editora Porto, 2001.

DE KETELE, Jean Marie. La formación didáctica y pedagógica de los profesores universitarios: luces y sombras. Revista de Educación, Madrid, n. 331, p. 143-169, 2003.

DESIMONE, Laura. Improving impact studies of teachers' professional development: toward better conceptualizations and measures. Educational Researcher, Thousand Oaks, v. 38, n. 3, p. 181-199, 2009.

ELTON, Lewis. Continuing professional development in higher education: the role of the scholarship of teaching and learning. Arts and Humanities in Higher Education, New York, n. 8, p. 247-258, 2009.

ESTRELA, Albano; ESTRELA, Maria Teresa. A formação contínua de professores numa encruzilhada. In: BIZARRO, Rosa; BRAGA, Fátima (org.). Formação de professores de línguas estrangeiras: reflexões, estudos e experiências. Porto: Editora Porto, 2006. p. 73-80. 
ESTRELA, Maria Teresa. Ética e pedagogia no ensino superior. In: LEITE, Carlinda (ed.). Sentidos da pedagogia no ensino superior. Porto: CIIE, 2010. p. 11-27.

FEIXAS, Mónica. El desenvolupament professional del professor universitari com a docent. 2002. Tese (Doutorado em Educação) - Universitat Autónoma de Barcelona, Barcelona, 2002.

FERNÁNDEZ CRUZ, Manuel. Desarrollo profesional docente. Granada: GEU,2006.

FLORES, Maria Assunção. Os professores em início de carreira e o seu processo de mudança: influências e percursos. Revista Educação, Lisboa, v. 12, n. 1, p.173-190, 2004.

FLORES, Maria Assunção; DAY, Christopher; VIANA, Isabel. Profissionalismo docente em transição: as identidades dos professores em tempos de mudança. Um estudo com professores portugueses e ingleses. In: FLORES, Maria Assunção; VIANA, Isabel (org.). Profissionalismo docente em transição: as identidades dos professores em tempos de mudança. Braga: Universidade do Minho, 2007. p. 7-46. (Cadernos CIED).

FULLER, Frances. Concerns of teachers: a developmental conceptualization. American Educational Research Journal, Thousand Oaks, p. 207-226, 1969.

GARCIA LÓPEZ, Rafaela. El professorado universitário ante la ética profesional docente. Revista Española de Pedagogia, Logrono, n. 235, p. 545-566, 2006.

GIBBS, Graham. Improving university teaching and learning trough institution-wide strategies. In: GIL, Victor; ALARCÃO, Isabel; HOOGHOFF, Hans (org.). Challenges in teaching and learning in higher education. Aveiro: Universidade de Aveiro, 2004. p. 149-166.

G00DWIN, David. Comprehensive development of teachers based on in-depth portraits of teacher growth. In: BEIJARD, Douwe et al. (org.). Teacher professional development in changing conditions. Netherland: Springer, 2005. p. 231-244.

Guellec, Dominique et al. OECD review of the tertiary rducation: research and innovation system in Portugal. Paris: OECD, 2018.

HARLAND, Tony; STANIFORTH, David. Contrasting views of induction: the experiences of new academic staff and their heads of department. Active Learning in Higher Education, Dorchester, v. 7, n. 2, p. 185-196, 2006.

HILL, Manuela Magalhães; HILL, Andrew. Investigação por questionário. 2. ed. Lisboa: Silabo, 2005.

ICED. INTERNATIONAL CONSORTIUM FOR EDUCATIONAL DEVELOPMENT. The preparation of university teachers internationally report. London: ICED Council, 2014.

KALIVODA, Pouline; SORREL, Geraldine; SIMPSON, Ronald. Nurturing faculty vitality by matching institucional interventions with career-stages needs. Innovative Higher Education, London, v. 18, n. 4, p. 255-272, 1994.

KATS, Eva; COLEMAN, Marianne. The influence of research on career development at academic colleges of education in Israel. Journal of Education for teaching, London, v. 28, n. 1, p. 45-61, 2002. 
KNIGHT, Peter; TAIT, Jo; YORKE, Mantz. The professional learning of teachers in higher education. Studies in Higher Education, London, v. 31, n. 3, p. 319-339, 2006.

KORTHAGEN, Fred. A prática, a teoria e a pessoa na aprendizagem profissional ao longo da vida. In: FLORES, Maria Assunção; SIMÃO, Ana Margarida (org.). Aprendizagem e desenvolvimento profissional dos professores: contextos e perspectivas. Mangualde: Pedagogo, 2009. p. 39-60.

KUGEL, Peter. How professors develop as teachers. Studies in Higher Education, London, v. 18, n. 3, p. 315- 329, 1993.

LEITE, Carlinda; RAMOS, Kátia. Questões da formação pedagógica-didáctica na sua relação com a profissionalidade docente universitária. Alguns pontos para debate. In: LEITE, Carlinda (ed.). Sentidos da pedagogia no ensino superior. Porto: ClIE, 2010. p. 29-45.

MARCELO, Carlos. Desenvolvimento profissional docente: Passado e futuro. Sísifo, Lisboa, n. 8, p. 7-22, 2009.

MORA, Carmen Fonseca; GÓMES, José Ignacio. Enseñar en la universidad: experiencias e propuestas para la docencia universitaria. Oleiros: Netbiblo, 2007.

MORAIS, Filomena; MEDEIROS, Teresa. Desenvolvimento profissional do professor: a chave do problema. Açores: DRCT, 2007.

MOREIRA, João Manuel. Questionário: teoria e prática. Coimbra: Almedina, 2004.

NYQUIST, Jody; SPRAGUE, Jo. Thinking developmentally about Tas. In: MARICONVICH, Michele; PROSTKO, Jack; STOUT, Frederic (org.). The professional development of graduate teaching assistants. London: Anker Publishing, 1998. p. 61-88.

PILL, Amanda. Models of professional development in the education and practice of new teachers in higher education. Teaching in Higher Education, Milton Park, v. 10, n. 2, p. 175-188, 2005.

PROSSER, Michael et al. Dissonance in experience of teaching and its relation to the quality of student learning. Studies in Higher Education, London, v. 28, n. 1, p. 37-48, 2003.

PROSSER, Michael et al. University academics' experience of research and its relationship to their experience of teaching. Instructional Science, Netherlands, n. 36, p. 3-16, 2008.

RAMSDEN, Paul. Learning to teach in higher education. London: Routledge Falmer, 2003.

ROBERTSON, Douglas. Professors' perspectives on their teaching: a new construct and developmental model. Innovative Higher Education, London, v. 33, n. 4, p. 271-294, 1999.

SHÖN, Donald. The reflective practicioner. New York: Basic Books, 1992.

TARDIF, Maurice. Saberes profissionais dos professores e conhecimentos universitários. Elementos para uma epistemologia da prática profissional dos professores e suas consequências em relação à formação para 0 magistério. Revista Brasileira de Educação, Rio de Janeiro, n. 13, p. 5-24, 2000. 
TILLEMA, Harm. Miroirs de l'autorégulation de l'apprentissage: les dilemmes des formateursd'enseignants. Revue des Sciences de l'Éducation, Montréal, v. 31, n. 1, p. 111-131, 2005.

TRIGWELL, Keith; PROSSER, Michael; WATERHOUSE, Fiona. Relations between teachers'approaches to teaching and students approaches to learning. Higher Education, London, n. 37, p. 57-70, 1999.

TRIGWELL, Keith; SHALE, Suzanne. Student learning and the scholarship of university teaching. Studies in Higher Education, London, v. 29, n. 4, p. 523-536, 2004.

TRIGWELL, Keith et al. Consonance and dissonance in descriptions of teaching of university teachers. Studies in Higher Education, London, v. 31, n. 1, p. 49-61, 2008.

TRIGWELL, Keith et al. How approaches to teaching are affected by discipline and teaching context. Studies in Higher Education, Lonon, v. 31, n. 1, p. 285-298, 2006.

TRIGWELL, Keith et al. Qualitative differences in approaches to teaching first year university science. Higher Education, London, n. 27, p. 75-84, 1994.

ZABALZA, Miguel. Competencias docentes del profesorado universitario: calidad y desarrollo profesional. Madrid: Narcea, 2007.

ZABALZA, Miguel. La enseñaza universitária: el escenario e sus protagonistas. Madrid: Narcea, 2004.

ZEICHNER, Kenneth. A formação reflexiva dos professores: ideias e práticas. Lisboa: Educa, 1993.

Recebido em: 05.03.2019

Revisado em: 15.08.2019

Aprovado em: 10.09.2019

Marta Almeida é doutora em educação pela Universidade de Lisboa, membro integrado da Unidade de Investigação e Desenvolvimento em Educação e Formação (UIDEF), exercendo a sua atividade como docente e pesquisadora no Instituto de Educação da Universidade de Lisboa. 